\title{
Entrepreneurship Ecosystem in Arab World: the status quo, impediments and the ways forward
}

\author{
Munira Aminova* \\ United Business Institutes, Brussels, \\ Belgium \\ E-mail: munira.aminova@ubi.be \\ Slaheddine Mareef \\ International Telecommunications Union, Geneva 20, \\ Switzerland \\ E-mail: slaheddine.maaref@itu.int \\ Carlos Machado, \\ Otto-von Guericke Universität Magdeburg, Magdeburg, \\ Germany \\ E-mail: carlos.machado@gekavoc.de
}

Received July, 2020; Accepted September, 2020

\begin{abstract}
This paper attempts to provide a holistic understanding of the environment in which entrepreneurs and SMEs and startups operate; the so-called entrepreneurial ecosystem in 22 Arab countries and proposes ways forward to stimulate and enrich the culture of entrepreneurship in the region. The ecosystem domain mapping, inspired by Isenberg's model, enabled to spot the gaps and constraints in the ecosystem. The measures to energize the ecosystem and the methods of intervention to stimulate entrepreneurship were done using GIZ model. The study concluded that much of the potential for digital entrepreneurship remains untapped by local entrepreneurs but eaten up by foreign businesses dominating the landscape. Thus, there is a high potential in the region for young and women entrepreneurs with the right type of skills and knowledge are instilled, and providing the entrepreneurial ecosystem is enabling. The paper provides some general recommendations and the ways forward.
\end{abstract}

Keywords: Arab Countries; Entrepreneurship; Entrepreneurial Ecosystem; Digital and Women Entrepreneurship; Startups.

Type: Research paper

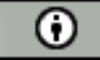

EY This work is licensed under a Creative Commons Attribution 4.0 International License.

DOI: 10.51325/ijbeg.v3i3.37

\section{Introduction}

Start-ups, small medium sized enterprises (SMEs) and entrepreneurs are the main drivers of world economy according to the World Business Angels Investment Forum (WBAIF). These micro, small - and medium - sized enterprises are the driving forces of economic stability, job creation, business innovation and green and inclusive growth. They recruit large majority of the working population of the world.

This report attempts to gain a holistic understanding of the environment in which entrepreneurs and SMEs operate; the so-called entrepreneurial ecosystem in 22 Arab countries; to gather and collect information related to the needs analysis on promoting entrepreneurial innovation culture with the focus on selected countries. It will then formulate guidelines for the acceleration strategy and priority training courses on entrepreneurship and digital skills amongst the young and not so young population, including women, to stimulate and enrich the culture of regional innovation and entrepreneurial ecosystem in the region. 
The methodology proposed will follow secondary data collection and primary research. The process will be to observe, analyze, visualize the entrepreneurial ecosystem, including surrounding institutions, culture and actors. The above ecosystem is then 'mapped' to enable to see the gaps and constrains in the ecosystem, and to devise the most relevant measures to energize the ecosystem in Arab region. The methodology closely follows the methodology of Deutsche Gesellschaft für Internationale Zusammenarbeit (GIZ) GmbH. The proposed methodology not only considers traditional indicators such as business environment and investment climate but also focus on behavioral and culture as influencing factors.

Entrepreneurship as an engine of economic growth is related to a combination of several determinants such as education levels, business climate and legal and political conditions (Alvarez et al. 2014). Some of the above listed factors explain the rates of entrepreneurship in a global context. They also can explain types of entrepreneurial activities carried out across countries and regions (Acs \& Amoros, 2008). Numbers of research activities were carried out which tried to explain a mix of determinants at the macro and micro level that lead to increase in entrepreneurship activities and processes (Reynolds et al. 1999). Extensive research also was carried out in analyzing institutional factors that determine the growth of entrepreneurship, and more specifically, the relevance of regulations in this process.

Based on the systems approach by Acs (2014), entrepreneurship is an action undertaken and driven by agents on the basis of incentives. Second, the individual action is affected by an institutional framework for entrepreneurship. Third, entrepreneurship ecosystems are complex, multifaceted structures in which many elements interact to produce systems performance, thus, the system method needs to allow the constituent elements to interact (Susan \& Acs, 2017).

Variations in entrepreneurship activity and the reasons behind the variation depends partially upon in institutional environment which defines, creates, limits entrepreneurial opportunities and thus affect entrepreneurial activity rates (Aldrich, 1990; Welter 2011., et al). Institutions are the rules of the game in a society, or more formally, institutions are constrains that shape human interaction. By providing stable structure for human interaction, institutions reduce uncertainty (North, 1990). Institutions can be formal, such as constitutions, regulations, contracts or informal such as culture, values, attitudes, behavioral norms of societies. Both institutions: formal and informal interact with each other and are interdependent. When formal institutions weaken informal institutions take over to govern the societies (Aminova, 2011, Alareeni, 2018). It is a blend of institutions (soft and hard) that drives knowledge production and application and how countries differ according to their set of institutions (Susan \& Acs, 2017). The knowledge is produced and accumulates through the interaction and innovation that is embedded in a national context. Thus the context of national country matters great deal with it comes to entrepreneurship and innovation outcomes.

On the other side of the spectrum there are a new breed of companies that emerged that uses digital technology. The success of companies like Uber, Snapchat, AirBnB and earlier Google, Amazon, Facebook and others is obvious. These companies use the breed of new technology, innovation and entrepreneurship to upend industries in a global scale (Stone, 2017). In order to better understand entrepreneurship at the digital world we use the concept of ecosystem. A system is a set of interacting and interdependent organizations that function together as a whole to achieve a purpose. An ecosystem is a purposeful collaborating network of dynamic interacting systems that have an ever-changing set of dependencies within a given context. (Susan \& Acs, 2017). 
The entrepreneurial ecosystem is a new way to contextualize the increasingly complex and interdependent social systems being created (Acs, et al., 2014).

As in the biological ecosystem, there is a nutrition and energy that is required for an ecosystem to survive and thrive. In the case of entrepreneurial ecosystem the nutrition is knowledge, creation and circulation of new knowledge and the energy is availability of funding according to Acs, 2014. However, the two are not enough, there is still a need for a production function which are - institutions and agents.

In this paper we rely on Isenberg's model on ecosystem domains which consists of policy, finance, culture, supports, human capital and markets. As can be seen from the Isenberg's figure, the entrepreneurship ecosystems are complex, multifaceted structures in which many elements interact to produce systems performance (Szerb, et al. 2014). Like in biological world, the ecosystem can flourish if all ingredients are sustainable and be destroyed if one of the components are cut off. In the entrepreneurial ecosystem we are talking about introducing heavier regulation or other. In the example of Silicon Valley we see that entrepreneurial ecosystem routinely produces high growth entrepreneurship, as all elements of the ecosystem are sustained to enable entrepreneurial growth.

Digital ecosystem have emerged as important research area as of early 2000s. Due to rapid digitization and advancement of digital technologies the subject area attracted discourse in multiple disciplines. There is wide divergence in terms of direction of research in relation to this area, but most research points to two founding pillars of the digital ecosystem: technologies and people. The technologies (e.g. Google) that enable people to use it are non-living part of the ecosystem and people (anyone who uses Google) are living part of the system.

The interaction and the process in this ecosystem is dynamic, resulting in multiple user driven changes and constant iterations in the ecosystem. The assumptions of such an ecosystem is user-driven, bottom-up, and open-source oriented (Dini et al. 2011).

\section{Context: The 22 Arab countries}

The countries of the League of Arab States (LAS) are: Algeria, Bahrain, Comoros, Djibouti, Egypt, Jordan, Iraq, Kuwait, Lebanon, Libya, Mauritania, Morocco, Oman, Palestine, Qatar, Saudi Arabia, Somalia, Sudan, Syria, Tunisia, United Arab Emirates, Yemen. The region is further classified into overlapping other clusters. Middle East and North Africa (MENA) is a big cluster grouping 19 out of 22 countries of Arab league. Gulf Cooperation Council (GCC) is another grouping that some countries belong to.

In most cases and for the ease of analysis the countries of Arab league are divided into several clusters given the wide variations in their socio-economic and political situations. We use the classification of O'Sullivant et al., (2016): 1) Resource-rich, labor-abundant: the countries in this cluster are producers and exporters of oil and gas. They also have their own large native populations. This group of countries includes Algeria, Iraq, Syria, and Yemen. 2) Resource-rich, labor-importing: the countries in this cluster are producers and exporters of oil and gas. They have large numbers of foreign or expatriate residents, who represent a significant percentage of the total population; in some cases it even represents the majority. This group of countries include the Gulf Cooperation Council (GCC) members (Bahrain, Kuwait, Oman, Qatar, Saudi Arabia, and the United Arab Emirates) and Libya. 3) Resource-poor: the countries in this cluster are small producers or importers of oil and gas, and include Djibouti, Egypt, Jordan, 
Lebanon, Mauritania, Morocco, Tunisia, and the Palestinian Authority. For the purposes of this paper we also add Sudan, Somalia and Comoros into this category.

MENA countries which represent majority of Arab countries are an important source of global stability due to their substantial petroleum and natural gas reserves. Oil and gas are primary commodities in the region whereas the share of finished goods remain low. There are large inequalities within the countries too. The gap between higher income group and lower income group is large. The poverty rate albeit decreasing the number of poor people didn't decrease for many years due to population increase rates. According to the World Bank 5\% of population in MENA region for instance are below 1,25\$ per day. Unemployment rate is high overall in the region. High unemployment rate amongst the youth include Egypt, Iran, Jordan, Lebanon, Libya, Tunisia and Yemen is observed.

On the bright side the region has a rich historical cultural and religious heritage according to Global Entrepreneurship Monitor (GEM). It is blessed with human, natural, and financial resources, and valuable biodiversity (GEM, 2018). The region is proclaimed as the cradle of civilizations is at the cusp of a potential entrepreneurship gold rush (McKinzey, 2018). MENA region is the most digitally connected region in the world, across the countries $88 \%$ of people are online daily, and $94 \%$ of people own a smartphone according to Global Mobile Industry Association (GSMA). Some countries like Saudi Arabia, leads the charts and represents $7^{\text {th }}$ place in the global ranking on social media engagement. Despite these indicators, the entrepreneurship potential is still yet to be fully tapped. According to McKinzey only $8 \%$ of SMEs have online presence which is 10 times less than US; the region only realized $8 \%$ of its overall digital potential. However, we can clearly observe the growth in entrepreneurship reflected in the number of successful start-ups and availability of funding for them.

\section{Methodology}

This report is based on secondary and primary data. Entrepreneurial ecosystem, including surrounding institutions, culture and actors were observed, analyzed and visualized. The above ecosystem is then 'mapped' to enable to see the gaps and constrains in the ecosystem, and to devise the most relevant measures to energize the ecosystem in Arab region. The methodology closely follows the recommended methodology Deutsche Gesellschaft für Internationale Zusammenarbeit (GIZ) GmbH. This methodology enables in a short time to design methods of intervention to stimulate entrepreneurship in the economy in general and in ICT sector in particular.

In the empirical part the following benchmark reports were used: Global Competitiveness Report from the WEF and Ease of Doing Business of the World Bank. The business environment and some selected components of the investment climate like the economic predictability, political situation and a labor market were analyzed in this category at the national level. Further the results of the above enabled to go in-depth to investment climate, and more precisely to understanding: financial markets, rule of law, labor market, political situation, infrastructure and economic predictability.

The data from Global Innovation Index from the World Intellectual Property Organization and Global Entrepreneurship monitor (GEM) from the Global Entrepreneurship Research Association was used in this paper too. The empirical analysis is based on the data available for most of the 22 Arab countries. For the missing data of certain year, the indicator of the following or proceeding year is used as an indicator. 
Figure 1. Framework for assessing entrepreneurship ecosystem and its success

\begin{tabular}{|c|c|c|}
\hline Access to Finance & Skilled Talent & Support and Networks \\
\hline $\begin{array}{l}\text { Individual investors } \\
\text { Venture capital funds } \\
\text { Public funding } \\
\text { Debt financing } \\
\text { Grant/subsidies } \\
\text { Securities market }\end{array}$ & $\begin{array}{l}\text { Access to education and general } \\
\text { degrees } \\
\text { R\&D and innovative skills } \\
\text { Access to local and international labor } \\
\text { market } \\
\text { Entrepreneurship training }\end{array}$ & $\begin{array}{l}\text { Acceleratorsincubators } \\
\text { Events } \\
\text { University-industry partnerships } \\
\text { Support: co-working spaces, } \\
\text { technoparks } \\
\text { Mentors, coaches, technical experts, } \\
\text { advisers }\end{array}$ \\
\hline Culture & Regulations and Policy & Market potential \\
\hline $\begin{array}{l}\text { Society's toward } \\
\text { entrepreneurship } \\
\text { Entrepreneurial role models } \\
\text { Media coverage } \\
\text { Ambition, drive, hunger } \\
\text { Social status of entrepreneur } \\
\text { Tolerance, risk, mistakes, failure }\end{array}$ & $\begin{array}{l}\text { Ease of doing business } \\
\text { Compliance } \\
\text { Trading across borders } \\
\text { Digital policies } \\
\text { Government R\&D policies } \\
\text { Venture-friendly legislation } \\
\text { Institutions }\end{array}$ & $\begin{array}{l}\text { Digital literacy / readiness: individual } \\
\text { use, cloud migration, digitization of } \\
\text { gov't services Domestic market size: } \\
\text { B2B, B2C, Public procurement } \\
\text { Local market efficiency } \\
\text { Internationalization }\end{array}$ \\
\hline ICT infrastructure & & \\
\hline $\begin{array}{l}\text { Accessibility and affordability of } \\
\text { Internet (mobile / fixed ) } \\
\text { Cloud \& data center experience }\end{array}$ & & \\
\hline
\end{tabular}

Inspired by OC\&C analysis and Isenberg's ecosystems domains

Global Information Technology Report of the World Economic Forum provides a Network Readiness Index of some 145 countries. The index takes into account four areas: environment (political and regulatory, business, and innovation), readiness (infrastructure, affordability, and skills), usage (individual, business, and government), and impact (economic and social). The methodology of this report and the outcome showcase that it is more than an infrastructure that is needed for fostering innovation and entrepreneurship.

The results of the report generate and lay the foundation for further research and debate about the role of entrepreneurial ecosystem that leads to economic growth and job creation. Due to vast differences between the socio-economic composition of the 22 Arab countries broad overall general recommendations and the ways forward were generated.

\section{Regulations and Policy}

There is a very large discrepancy within the region when it comes to socioeconomic, political, legal and other indicators. Out of 22 countries of Arab league on the indicator of Ease of Doing Business (World Bank, 2018) some countries like United Arab Emirates are amongst the leading countries when it comes to ease of doing business score. UAE is on the $11^{\text {th }}$ rank amongst 190 countries of the world, thus making 
it not only a regional leader but also one of the top countries when it comes to ease of doing business. Despite the fact that the ecosystem in UAE is relatively young and most of the regulatory aspects are still in the phase of development. In the last couple of years UAE introduced a number of regulatory changes to ease doing business e.g. improved online registration processes for businesses, eased the requirements for obtaining electricity and construction permits, introduced new service centers and a standard for contract for property transactions and many others (WB, 2019).

It is followed by Morocco and Bahrain respectively which are on the 60th and 62nd rank among the 190 countries. Morocco also introduced a number of regulatory changes to ease doing business e.g. the country abolished the deed registration fee and stamp duties, reduced registration fees for new businesses and introduced an online platform to reserve the company name, reduced company registration fees, made dealing with construction permits easier by opening a one-stop shop, made registration of property easier by increasing transparency of the land registry and cadaster and by further streamlining the administrative procedures and others (WB, 2019). As a direct result we will see further that the number of registration for new businesses in Morocco is highest in the Arab would. Oman, Tunisia and Qatar follow the chart after Morocco and Bahrain offering relative ease of doing business to their entrepreneurs and business people.

The many reforms to streamline the regulations and create further conditions have been put in place. Ease of doing business report classifies some countries like Somalia (190th) and Yemen (187th) as least favorable when it comes to doing business. While no major regulatory changes were observed in the case of Somalia, Yemen was noted as making the starting of the business more difficult due to suspension of registration services at the one-stop shop.

\section{Entrepreneurship in Arab countries}

Overall people in Arab countries have largely positive attitudes toward entrepreneurship (GEM, 2017)1. On average almost three quarters of people in the region see entrepreneurship as a good career choice, especially in MENA region. (GEM, 2017). The governments of MENA region made concerted efforts to stimulate entrepreneurship in their countries.

Below is the representation of the societal values about entrepreneurship in eight Arab countries which participated in GEM survey in 2016. Tunisia participated in 2015. Societal values and perceptions albeit not direct contributors to the success of entrepreneurial ecosystem but have a strong indirect impact. The way people perceive entrepreneurship depends how many people will risk taking on entrepreneurial activities. As we see from the table below on average on the eight countries representing the region we see that two thirds of population have a positive perception of entrepreneurship: they see entrepreneurship as a good career choice; successful entrepreneurs have high status, and media has attention is also high in comparison to the world average.

Out of 22 countries of Arab world only 13 participated in GEM study in different years. The rest of the data ${ }^{1}$ was collected from additional sources. 
Table 1: Societal values about entrepreneurship in Arab countries

\begin{tabular}{|l|c|c|c|}
\hline & $\begin{array}{l}\text { Entrepreneurship } \\
\text { as a good career } \\
\text { choice (\% of } \\
\text { adult population) }\end{array}$ & $\begin{array}{l}\text { High status to } \\
\text { successful } \\
\text { entrepreneurs } \\
\text { (\% of adult } \\
\text { population) }\end{array}$ & $\begin{array}{l}\text { Media attention } \\
\text { for } \\
\text { entrepreneurship } \\
\text { (\% of adult } \\
\text { population) }\end{array}$ \\
\hline Egypt & $83.4^{*}$ & 87.1 & 62.1 \\
\hline Iran & 52.4 & 80.5 & 57.9 \\
\hline Jordan & 73.5 & 82.3 & 74.7 \\
\hline Morocco & 79.3 & 58.7 & 60.7 \\
\hline Qatar & 71.2 & 80.4 & 66.7 \\
\hline Saudi Arabia & 81.3 & 78.7 & 75.9 \\
\hline $\begin{array}{l}\text { Tunisia } \\
\text { (2015) }\end{array}$ & 71.1 & 72.1 & 48.3 \\
\hline UAE & 75.1 & 82.3 & 83.8 \\
\hline $\begin{array}{l}\text { Average } \\
\text { (MENA) }\end{array}$ & 73.4 & 77.8 & 66.3 \\
\hline
\end{tabular}

Source of data: GEM, 2016

More specifically we can see that United Arab Emirates (UAE), Saudi Arabia and Egypt have a very high positive perception of entrepreneurship whereas Iran has the lowest positive indicator. Only half of the population of Iran for example sees entrepreneurship as a good career choice.

Table 2: Fear of failure

\begin{tabular}{|c|l|c|c|}
\hline & \multicolumn{1}{|c|}{ Country } & $\begin{array}{c}\text { Fear of } \\
\text { failure rate }\end{array}$ & $\begin{array}{c}\text { Female/Male } \\
\text { TEA }\end{array}$ \\
\hline $\mathbf{1}$ & Lebanon & 17.02 & 0.69 \\
\hline $\mathbf{2}$ & Egypt & 30.2 & 0.4 \\
\hline $\mathbf{3}$ & Algeria & 32.95 & 0.51 \\
\hline $\mathbf{4}$ & Libya & 33.05 & 0.49 \\
\hline $\mathbf{5}$ & Saudi Arabia & 34.35 & 0.83 \\
\hline $\mathbf{6}$ & Palestine & 40.19 & 0.21 \\
\hline $\mathbf{7}$ & Tunisia & 40.25 & 0.36 \\
\hline $\mathbf{8}$ & Qatar & 41.86 & 0.99 \\
\hline $\mathbf{9}$ & Jordan & 44.34 & 0.26 \\
\hline $\mathbf{1 0}$ & Morocco & 52.9 & 0.37 \\
\hline $\mathbf{1 1}$ & United Arab & 61.08 & 0.89 \\
\hline
\end{tabular}

Source of data: GEM, 2016

The table above shows in the first column the Percentage of 18-64 year old population perceiving good opportunities to start a business who indicate that fear of failure would prevent them from setting up a business. As we see that in some countries the level of tolerance for failure is much higher than in the others. The highest percentage of 18-64 year old population perceiving failure as an impediment to start their own business is $61.08 \%$ in the United Arab Emirates. Despite the ease of doing 
business in UAE the fear of failure is the highest within the 11 countries who participated in GEM survey.

On the contrary in Lebanon the fear of failure is lowest and represents only $17.02 \%$ of the 18-64 year old population who even though perceive good opportunities to start business but who fear failure. Looking at the historical data fear of failure rate is historically low in Lebanon. The data is not available for all the 22 countries of Arab league to enable more in-depth discussion.

Another very important indicator of business and entrepreneurial activity which is Percentage of female 18-64 population who are either a nascent entrepreneur or owner-managers of a new business, divided by the equivalent percentage for their male counterparts.

Qatar has almost equal representation of women entrepreneurs equaling to $0.99 \%$, followed by United Arab Emirates and Saudi Arabia. The alarmingly low ratio remains in Palestine and Jordan 0.21 and $0.22 \%$ consequently, which signifies that for every five entrepreneur only one is a woman. Overall score in the region is $0.52 \%$.

When it comes to the most enabling environments and ecosystems for entrepreneurship amongst the 11 countries of Arab league the most enabling environment is of United Arab Emirates and Qatar. In most of the indicators representing entrepreneurial framework condition the two countries score highly. The least favorable conditions seem to appear in Iran, especially in the areas of entrepreneurial finance, government entrepreneurship programs, internal entry burdens and market regulations. Iran was classified as least favorable due to the fact that only 11 countries took place in this analysis. If the other 11 countries would participate the regional conclusions would be much more divergent.

\section{Access to finance}

There are myriad of multiple players and stakeholders, as well ecosystem members like accelerators, co-working spaces, incubators and other support mechanisms that are present in most of the Arab countries especially in MENA countries. The number of venture capitalists, angel investors and other funding organizations are more and more attracted to MENA region. According to the preliminary estimates the funding has significantly increased from $\$ 53$ million in 2014 to $\$ 410$ million in 2017 (McKinzey, 2018). 
Figure 1: Incubators, accelerators and co-working spaces in Arab region
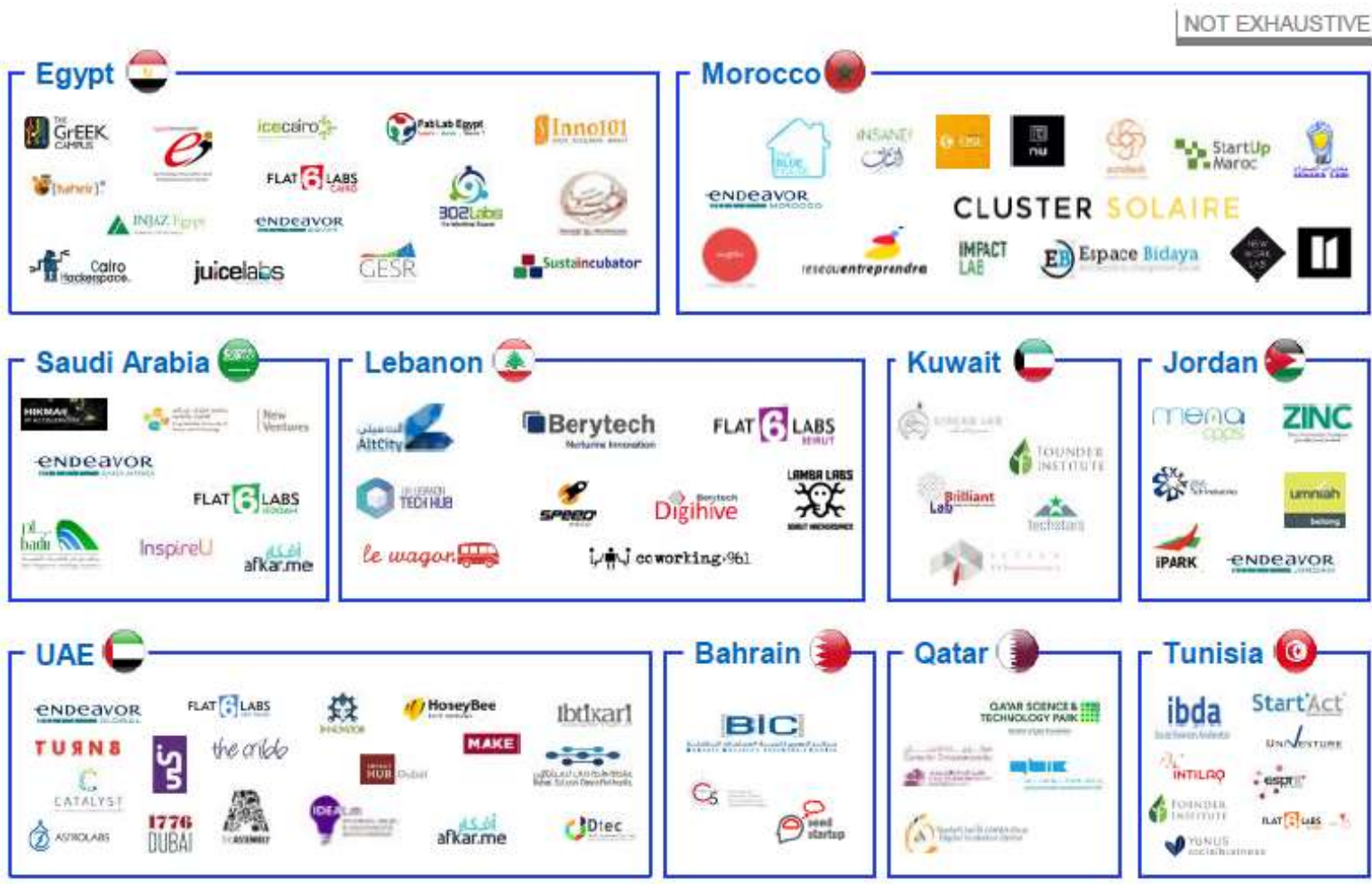

Source: McKinzey, 2018

The number and the amount of funding of venture capitalists have outgrown expectations for the region. Having countries with large oil reserves the region easily attracts funding for new ventures. The sale of Souq.com by Amazon and the return on investment was one of the good examples of potential the region has. Apart from private sector funding there is certainly government funding and government led initiatives that are directed on the growth of the ecosystem and toward the support of the entrepreneurship in the region.

UAE is a good examples for setting a scene as a pioneer in its startup ecosystem. Dubai Future Accelerators for instance is one example of initiatives which backs up innovative high-growth ventures that use the innovation to increase productivity and contribute to economic growth. Saudi Arabia's government also contributed significant amount of investments through the Vision Fund and SMEA. They also have joint ventures in this domain between Japan's SoftBankGroup and PIF of Saudi Arabia. This fund was created to promote the tech entrepreneurship and AI domain. The government of Lebanon committed 400mln worth of investment into knowledge economy.

\section{Conclusions}

The availability of the new and affordable digital tools gives unprecedented opportunity to the young people to leapfrog the traditional hurdles and jump start their business in the comfort of their homes. Both the number of younger tech savvy population, and the exponential development in digital technologies and digital consumption are in the growth at Arab countries. Much of the potential for digital entrepreneurship remains untapped by local entrepreneurs but eaten up by foreign businesses dominating the landscape. 
The role of private and public investors is important for future growth of entrepreneurship in the region. Further development of entrepreneurial ecosystems in Arab countries will need benefit from entrepreneurial education, government support, and financial resources.

\section{Generic recommendations}

This report provided a summary of existing situation as well as the summary of actions taken within different countries to further promote entrepreneurship and digital skills in their countries and in Arab region in general. Due to wide variance between the countries and their socio-economic situations, the recommendations of this report provide a general guidance and direction for action rather than a blueprint to follow step by step.

By researching the ecosystems of the Arab region it became evident that starting from the remote village in Djibouti to an advanced city in UAE every place has its own unique ecosystem with its richness and opportunities and of course with its challenges. In most of the cases it takes human ingenuity, a pioneers spirit and a long term vision to exploit the potential fully. It's equally about taking risks and connecting actors to quadruple helix - citizens, businesses, administration and academia. The ecosystems evolve in most cases thru the interaction between top-down policy makers and their choices and bottom up creative individuals. Thus it's a combination of public provision and private initiative.

Below are some general recommendations which emerged from this research that would further the development of ecosystems within the 22 Arab countries:

\section{Join efforts and consolidate the experiences between the 22 Arab countries}

Building bridges and bringing together the different players - investors, accelerators, entrepreneurs, corporate networks, universities and the media - together within the ecosystem of Arab countries will lead to further coherence and create more opportunities. The consolidated networks and ecosystems will provide the right ground for structured and effective growth for Arab startups and entrepreneurs. Examples could be Single digital gateway hackathons with the participation of multiple countries and cities and teams; Student entrepreneurship annual summits - which could bring early stage entrepreneurs and students together; to encourage women entrepreneurship Women's coding events could be organized on a regional level; and many others. These types of efforts provide an additional incentive to entrepreneurs to keep innovating and prototyping their solutions. This integration and cooperation will allow the entrepreneurs to take a step further and follow their vision and experiment with new markets, technologies and innovations.

\section{Provide training sessions to entrepreneurs on digital skills based on the identified}

\section{training needs analysis}

The digital skills and competences is an important parameter for the furthering entrepreneurship in Arab countries. Developing a talent pool and ensuring that young entrepreneurs and women are equipped with adequate digital skills will require concerted efforts of public authorities primarily but also of businesses, academia and other stakeholders. Availability of resources and projects supporting the development of digital skills from International organizations and supranational governments is paramount. 
To boost and involve the businesses and other organizations in boosting the digital skills will enable countries to leapfrog the development and funding hurdles of needing to make large investments from the very beginning. Google Atelier provides for examples training on coding, web design, content creation, digital marketing and other skills for free in most of the countries.

\section{Connect young entrepreneurs to training and mobility exchange opportunities}

\section{both abroad and within the Arab countries}

Creating a platform where providers and users can meet and exchange is one of the ways of getting stakeholders engaged from providers and users sides. European Commission's Digital Opportunity traineeships can be used by organizations who provide a possibility to have a digital traineeships to the students who want to do internships in the area which involved digital skills.

Creating new opportunities and safety nets will further enable turning the Arab region to an emerging hub for technology and innovations.

\section{Transform ArtecNet into Arab Tech Startup Hub}

Creating a One Stop Shop and a platform for all stakeholders is what is missing in Arab world. This would unite the efforts and bring ArtecNet as a pioneer for promoting digital and tech entrepreneurship.

Digital entrepreneurship is at rise in the Arab countries. Tech savvy younger generation and exponential evolution in technologies can help further boost digital presence in the region.

Digital technologies have a capacity to substantially change the way we design, produce, commercialize and create value. Arab countries can leapfrog and take advantage of the full potential of these digital technologies and digital revolution, using the examples of each other. This can lead to better integration and create further growth and create more job opportunities.

Dr. Munira Aminova obtained her PhD in Political Sciences from Vrije Universiteit Brussel in 2011. Her research focuses on entrepreneurship and on public administration and governance. She has worked in multiple projects with the UN and and the European Commission on the projects as TEMPUS, ERASMUS+, Marie Curie and others.

Mr. Slaheddine Maaruf has worked for over 7 years in the International Telecommunication Union as a senior adviser. Previously, he was in various managing roles including in the Ministry of ICT of Tunisia for over 19 years. He has graduated with the engineering degree in telecom industry from France.

Dr. Carlos Machado was awarded with a PhD in Social Sciences by Vrije Universiteit Brussel in 2006. Since 2008 he has been involved in capacity building projects in the area of research, innovation and entrepreneurship first with Central Asia and then in Middle East and Asia through TEMPUS and Erasmus+ programs.

This research was funded by the International Telecommunications Union as a part of the project on Entrepreneurship and Innovation under the auspices of Arab Initiative as approved by World Telecommunications Development Conference (WDTC) 17 to build 
capacities and raise awareness concerning the culture of innovation and entrepreneurship in the region.

\section{References}

Alareeni, B. (2018). Does corporate governance influence earnings management in listed companies in Bahrain Bourse?, Journal of Asia Business Studies, 12(4), 551-570. https://doi.org/10.1108/JABS-06-2017-0082

Aminova, M., \& Jegers, M. (2011). Informal structures and governance processes in transition economies: The case of Uzbekistan. International Journal of Public Administration, 34(9), 579-590. https://doi.org/10.1080/01900692.2011.588436

ASK Life in Kuwait (image in the $2^{\text {nd }}$ page with flamingos) Retrieved February 1st, 2019 from https://www.ask.edu.kw/life-in-kuwait

ASPEN Network of Development Entrepreneurs. (2015). Entrepreneurial ecosystem diagnostic toolkit. Supported by UKAID. Last accessed 21.03.2019 at https://assets.aspeninstitute.org/content/uploads/files/content/docs/pubs/FINAL\%2 0Ecosystem\%20Toolkit\%20Draft_print\%20version.pdf

Castells, M. (1996). The rise of the network society. Wiley-Blackwell Publishing.

European Bank for Reconstruction and Development, European Investment Bank, \& The World Bank. (2016). What's holding back the private sector in MENA? Lessons from the Enterprise Survey. Washington, DC: The World Bank

European commission. (2016). Skills agenda for Europe.

GEM Global Entrepreneurship Monitor. (2017, 2018). Last accessed on 5.06.2020 at https://www.gemconsortium.org/report/gem-2017-2018-global-report.

GSMA. (2018) .The mobile gender gap report 2018. Accessed on $8^{\text {th }}$ March 2019 at

GSMA. (2016). The mobile economy, Middle East and North Africa. GSMA Intelligence. Last accessed on 21.02.2019 at www.wearesocial.com.

Hijab Stock Photos (Title page image). Retrieved February 1st, 2019 from https://www.dreamstime.com/photos-images/hijab.html

https://www.gsma.com/mobilefordevelopment/connected-women/the-mobile-gendergap-report-2018/

IFC. (2007). Women entrepreneurs in the Middle East and North Africa: Characteristics, contributions and challenges (working paper).

Kauffman. (2017). The Kauffman Index. Startup activity: Metropolitan Area and City Trends https://www.kauffman.org/kauffmanindex/reporting/ /media/9f685e8c214248f0884fa21416f6b03e.ashx

Laurinavicius, T. (2016). Ten digital skills you need to master to become an entrepreneur. Observer accessed on the $13^{\text {th }}$ March 2019: https://observer.com/2016/10/ten-digital-skills-you-need-to-master-to-become-anentrepreneur/

McKinsey Global Institute. (2013). Lions go digital: the internet's transformative potential in Africa. Retrieved at www.mckinsey.org

McKinzey.(2018). Entrepreneurship in the Middle East and North Africa: How investors can support and enable growth. McKinzey publications.

Mikkonen, M. (2015). Influence of the entrepreneurship and innovation ecosystem on university-based startups. A case study of Aalto University. Last accessed https://aaltodoc.aalto.fi/handle/123456789/18422, the $8^{\text {th }}$ Nov 2018

OC\&C Strategy Consultants. (2019). Tech entrepreneurship ecosystem in the United Arab Emirates. Commissioned by Google. Accessed last 21.03.2019 https://s3-eu- 
west-1.amazonaws.com/wamda-prod/labreports/TechEntrepreneurship_UAE_Report.pdf

OECD. (2015). The innovation imperative: Contributing to productivity, growth and well-being. OECD Publishing, Paris. https://doi.org/10.1787/9789264239814-en

OECD. (2017). Entrepreneurship at a Glance. OECD publishing, Paris

Suresh, J., \& Ramraj, R. (2012). Entrepreneurial ecosystem: Case study on the influence of environmental factors on entrepreneurial success. European Journal of Business and Management, 4(16), 95-101.

The World Bank. (2019). Doing Business 2019: Training for Reform - Regional profile: Arab World. The World Bank Publications.

The World Bank. (2019). Doing Business 2019: Training for Reform - Regional profile: Arab World. The World Bank Publications.

UNDP. (2018). Human development reports. Statistical update accessed on $12^{\text {th }}$ March 2019 at http://hdr.undp.org/en/composite/Dashboard3

UNESCO. (2009). Institute for World Statistics accessible online at http://uis.unesco.org/en/glossary-term/gross-enrolment-ratio

WEF. (2016). The Global information technology report. World Economic Forum $\begin{array}{lllll}\text { accessed } & \text { on } & 8^{\text {th }} & \text { March } & 2019\end{array}$ http://www3.weforum.org/docs/GITR2016/WEF_GITR_Full_Report.pdf

World Bank. (2016) World development report: Digital dividends. Retrieved on $22^{\text {nd }}$ Feb

http://documents.worldbank.org/curated/en/961621467994698644/pdf/102724WDR-WDR2016Overview-ENGLISH-WebResBox-394840B-OUO-9.pdf

World Bank. (2016). World development report, Washington, DC.

World Business Angels Forum. (2018). For Entrepreneurship and innovation ecosystem leaders: A Step-by-Step country master plan to create and drive a healthy early stage investment. Market for Your Country/Region, last accessed from http://wbaforum.org/for-entrepreneurship-innovation-ecosystemleaders/index.html, the $8^{\text {th }}$ Nov 2018

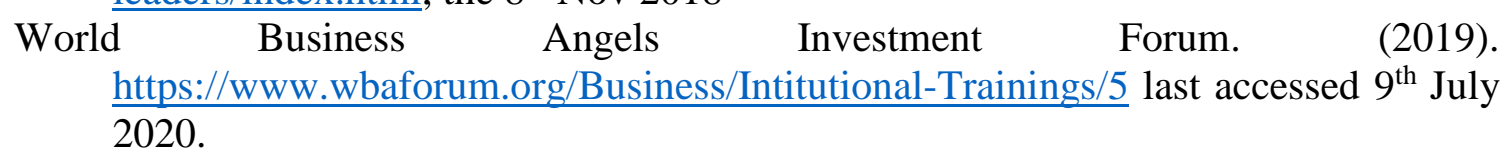

